\title{
Adsorption Properties and Cost of Dicarboxylic Nanocellulose on Copper Ions for Wastewater Treatment
}

\author{
Xiaozheng Sun ${ }^{1, *}$, Yu Yang ${ }^{1}$, Qiang $\mathrm{He}^{2}$, Jianye $\mathrm{Li}^{1}$, Rui $\mathrm{Li}^{1}$ and Haitao Chen ${ }^{1}$ \\ ${ }^{1}$ College of Engineering, Northeast Agricultural University, Harbin, 150030, China \\ ${ }^{2}$ College of Mechanical Engineering, Jiamusi University, Jiamusi, 154007, China \\ *Corresponding Author: Xiaozheng Sun. Email: sxz1976@hotmail.com \\ Received: 21 April 2021 Accepted: 21 May 2021
}

\begin{abstract}
The accumulation of $\mathrm{Cu}^{2+}$ in water is a potential threat to human health and environment. Dicarboxylic nanocellulose (DNC) with rich carboxyl groups was prepared through the $\mathrm{NaIO}_{4}-\mathrm{NaClO}_{2}$ sequential oxidation method to efficiently remove copper ions, and the $\mathrm{Cu}^{2+}$ adsorption properties and cost were studied. The maximum adsorption capacity reached $184.2 \mathrm{mg} / \mathrm{g}$ at $\mathrm{pH} 6$ and an adsorbent dose of $5 \mathrm{~g} / \mathrm{L}$. Theoretically, the maximum adsorption capacities of monocarboxylic nanocellulose (MNC), DNC, and tricarboxylic nanocellulose (TNC) with carboxyl groups as the main adsorption sites were calculated to be $228.7,261.3$, and $148.1 \mathrm{mg} / \mathrm{g}$, respectively. The $\mathrm{Cu}^{2+}$ adsorption costs of MNC, DNC, and TNC were calculated and compared with those of powdered activated carbon (PAC). The $\mathrm{Cu}^{2+}$ adsorption capacity of DNC is higher than that of PAC, and the adsorption cost is close to or lower than that of PAC, demonstrating that the DNC prepared by sequential oxidation of $\mathrm{NaIO}_{4}-\mathrm{NaClO}_{2}$ has competitive adsorption capacity and cost in the treatment of wastewater containing $\mathrm{Cu}^{2+}$.
\end{abstract}

\section{KEYWORDS}

Nanocellulose; heavy metal ions; maximum adsorption capacity; adsorption cost

\section{Introduction}

The rapid development of industrial and agricultural products since the $20^{\text {th }}$ century has led to the gradual accumulation of heavy metal ions in soil and water. Heavy metal ions accumulate in the human body through the transmission of the food chain, causing irreversible harm [1]. Copper ions are the most common heavy metal pollutants in industrial effluents and may accumulate in the human liver, posing serious threat to health [2]. Therefore, the removal of $\mathrm{Cu}^{2+}$ from wastewater has attracted increasing attention.

Adsorption is one of the most common approaches for removing heavy metal ions from aqueous solutions. This method mainly exploits the porosity, high specific surface area, and high surface activation energy of the adsorbent to remove heavy metal ions from water by surface complexation, hydrogen bonding, and electrostatic attraction. Common adsorbents include activated carbon, ionexchange fibers, modified cellulose, and other materials [3]. Activated carbon is a material with abundant oxygen-containing functional groups on its surface, which are conducive to the adsorption of heavy metals. Ion-exchange fibers adsorb heavy metal ions through ion exchange between the exchange groups 
attached to the fibers. Graft copolymerization or the introduction of functional groups to modify the fibers can improve their adsorption capacity, but the recyclability and reusability of ion-exchange fibers are relatively weak [4].

Biomass is a renewable resource, so the use of biomass to prepare various biomass materials instead of non-renewable materials has become a research hotspot $[5,6]$. Nanocellulose is a class of cellulose materials with at least one dimension in the range of 1-100 $\mathrm{nm}$ [7-9]. It has a high specific surface area, excellent mechanical properties, and environmental friendliness, and is widely used in polymer reinforcement materials, heavy-metal ion adsorption, and oxygen-barrier packaging materials [10-12]. Carboxylic nanocellulose contains active carboxyl groups in the cellulose chains, thus providing more reactive sites, and has a high specific surface area, enhancing its ability to remove metal ions from water [13].

Studies have shown that the increase in the carboxyl content of nanocellulose enhances its interaction with positively charged heavy metal ions; thus, nanocellulose with higher carboxyl content has a strong adsorption capacity for heavy metal ions $[14,15]$. Therefore, many studies have focused on increasing the carboxyl content of nanocellulose to improve the amount of metal ions adsorbed [16-18]. TEMPO (2,2,6,6-tetramethylpiperidine-1-oxyl)-mediated oxidation and periodate oxidation are two commonly used methods to increase the content of carboxyl groups on the surface of nanocellulose [19]. The TEMPO-mediated oxidation method can selectively convert hydroxyl groups at the $\mathrm{C} 6$ sites of nanocellulose to carboxyl groups [20]. The hydroxyl groups at $\mathrm{C} 2$ and $\mathrm{C} 3$ can be selectively oxidized to carboxyl groups by sequential oxidation using sodium periodate $\left(\mathrm{NaIO}_{4}\right)$ and sodium chlorite $\left(\mathrm{NaClO}_{2}\right)$ [9]. The adsorbed amount of $\mathrm{Cu}^{2+}$ reached $75.0 \mathrm{mg} / \mathrm{g}$ using monocarboxylic nanocellulose (MNC) prepared by TEMPO-mediated oxidation [20]. Dicarboxylic nanocellulose (DNC) adsorbed $246.0 \mathrm{mg}$ $\mathrm{Cu}^{2+}$ per gram at $\mathrm{pH} 4.6$ [21]. Tricarboxylic nanocellulose (TNC) was prepared by TEMPO-mediated oxidation of pulp followed by periodate-chlorite oxidation [13], and the adsorption capacity of $\mathrm{Cu}^{2+}$ was $97.3 \mathrm{mg} / \mathrm{g}$. Carboxymethylated cellulose has a carboxyl content of $2.7 \mathrm{mmol} / \mathrm{g}$ and an adsorbed $\mathrm{Cu}^{2+}$ amount of $115.3 \mathrm{mg} / \mathrm{g}$ [22]. However, Under the condition that nanocellulose maintains the morphology of intact cellulose microfibrils, the theoretical maximum adsorption capacity of $\mathrm{Cu}^{2+}$ onto nanocellulose has not been reported.

In addition, the adsorption capacity and cost of adsorbent are the two most important factors to optimize for the adsorption process to be economically feasible. Currently, activated carbon is still the main metal-ion adsorbent commonly used in the market. Granular activated carbon (GAC) and powdered activated carbon (PAC) are the two forms of activated carbon that are usually applied. Carboxylic nanocellulose is usually powdered, so it is fair to compare the adsorption cost of carboxylic nanocellulose with that of PAC. In 1995 , the prices of PAC were around $\$ 0.80-2.00$ per $\mathrm{kg}$ in the USA and \$0.70-1.50 per $\mathrm{kg}$ in Europe [21]. PAC cannot be reactivated because the average total regeneration costs are approximately $\$ 0.70$ 0.85 per $\mathrm{kg}$ (i.e., close to production cost); therefore, PAC is used as a one-way adsorbent [23]. However, the price of nanocellulose fluctuates widely, ranging from \$60-1200 per kg (dry weight) in Europe [24], and carboxylic nanocellulose can be regenerated and recycled to remove heavy metal ions [14]. It is inconclusive whether carboxylic nanocelluloses can compete with PAC in terms of adsorption cost.

In this study, microcrystalline cellulose (MCC) was used as the raw material, and DNC was prepared using the $\mathrm{NaIO}_{4}-\mathrm{NaClO}_{2}$ sequential oxidation method. The effects of initial $\mathrm{pH}$, initial $\mathrm{Cu}^{2+}$ concentration, and adsorbent dose on the adsorbed amount were investigated. The adsorption kinetics and isotherm models are discussed. In addition, the theoretical maximum adsorption capacities of $\mathrm{Cu}^{2+}$ onto MNC, DNC, and TNC were calculated, and the $\mathrm{Cu}^{2+}$ adsorption costs of MNC, DNC, and TNC were compared with those of PAC. This study can provide a scientific basis for the development of renewable nano-adsorbents with high adsorption capacity and low cost. 


\section{Materials and Methods}

\subsection{Materials}

All chemicals used in this study were of reagent grade and used as received without further purification. All test water was deionized, and all chemicals were purchased from Chemical Reagent Co., Ltd., China National Medicine Group, China.

\subsection{Methods}

\subsubsection{Preparation of DNC}

DNC was prepared using a previously reported method [9]. Specifically, $4 \mathrm{~g} \mathrm{MCC}, 5.33 \mathrm{~g} \mathrm{NaIO}_{4}$, and $15.6 \mathrm{~g} \mathrm{NaCl}$ were dispersed in deionized water. The reaction beaker was wrapped by aluminum foil to prevent degradation of the $\mathrm{NaIO}_{4}$ caused by light irradiation. The oxidation reaction was carried out for $24 \mathrm{~h}$ at room temperature (RT). Ethylene glycol was used to quench the reaction. The oxidized MCC was thoroughly washed using deionized water by centrifugation $(1500 \mathrm{~g}, 5 \mathrm{~min})$ until the conductivity of the supernatant was less than $30 \mu \mathrm{S} / \mathrm{cm}$. The precipitate was dried using a freeze dryer.

One gram of the dried precipitate was suspended in $50 \mathrm{~mL}$ water and $2.93 \mathrm{~g} \mathrm{NaCl} ; \mathrm{NaClO}_{2}$ and $\mathrm{H}_{2} \mathrm{O}_{2}$ (with molarities twice that of the aldehyde content of the dried precipitate) were added to this mixture. The mixture was stirred at RT for $24 \mathrm{~h}$, and the $\mathrm{pH}$ was maintained at 5.0 by adding $\mathrm{NaOH}(0.5 \mathrm{M})$. After the reaction, the oxidized product was washed with deionized water by centrifugation at $8500 \mathrm{~g}$ for $5 \mathrm{~min}$. After the conductivity of the supernatant dropped to less than $30 \mu \mathrm{S} / \mathrm{cm}$, the dried DNC was obtained by drying in a vacuum freeze dryer.

\subsubsection{Characterization of DNC}

The morphology of DNC was observed and analyzed using transmission electron microscopy (TEM; JEM-2100, Japan Electronics Corporation, Japan) and field-emission scanning electron microscopy (FE-SEM; JSM-7401F, JEOL, Ltd., Japan), respectively. Fourier-transform infrared spectroscopy (FTIR; Nicolette 6700, Nicolette, USA) was used to acquire the infrared spectrum of the DNC. X-ray diffraction analysis (XRD; D/max-2200VPC type, Nippon Science Co., Ltd., Japan) was used to characterize the nanocellulose in terms of crystal form and crystallinity. The diffraction patterns were background corrected to remove any signal from the sample holder. Data from a blank run including the sample holder were subtracted from the data of experimental samples [25]. The carboxyl contents of DNC were determined by conductometric titration in previously reported method with the following Eq. (1). The crystallinity index (CI) was determined using the Segal method [26-28] with the following Eq. (2).

$\left[\mathrm{COO}^{-}\right]=\frac{\left(\mathrm{V}_{\mathrm{NaOH}(\text { added })}-\mathrm{V}_{\mathrm{HCL}}\right) \times \mathrm{M}_{\mathrm{NaOH}}}{\mathrm{W}_{\mathrm{CEL}}}$

where $\left[\mathrm{COO}^{-}\right]$is carboxyl content $(\mathrm{mmol} / \mathrm{g}) ; V_{\mathrm{NaOH} \text { (added) }}$ is the volume of $\mathrm{NaOH}$ at the inflection point $(\mathrm{mL}) ; V_{\mathrm{HCl}}$ is the volume of $\mathrm{HCl}$ added to the $0.1 \mathrm{M} \mathrm{HCl}-0.5 \mathrm{M} \mathrm{NaCl}$ mixed solution $(\mathrm{mL}) ; M_{\mathrm{NaOH}}$ is equivalent concentration of $\mathrm{NaOH}(\mathrm{mol} / \mathrm{L}) ; W_{C E L}$ is starting mass of $\mathrm{DNC}(\mathrm{g})$.

$\mathrm{CI}=\frac{\mathrm{I}_{200}-\mathrm{I}_{\mathrm{am}}}{\mathrm{I}_{200}} \times 100 \%$

where $\mathrm{I}_{200}$ is the maximum diffraction intensity at $2 \theta$ between $22^{\circ}$ and $23^{\circ} ; \mathrm{I}_{\mathrm{am}}$ is the minimum diffraction intensity at $2 \theta$ between $18^{\circ}$ and $19^{\circ}$ [27].

\subsubsection{Adsorption Experiments}

Batch adsorption experiments were conducted to explore the effects of the initial $\mathrm{pH}$ value (1-6), adsorbent dose $(2.5-25 \mathrm{~g} / \mathrm{L})$, initial $\mathrm{Cu}^{2+}$ concentration $(51.6-1014.0 \mathrm{mg} / \mathrm{L})$, and contact time $(2 \mathrm{~h})$ on the 
adsorption capacities of $\mathrm{Cu}^{2+}$ ions. Specifically, a designated amount of adsorbent was introduced into a

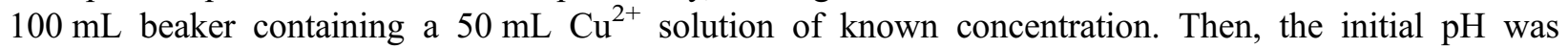
adjusted precisely to the desired value with $0.1 \mathrm{M} \mathrm{HCl}$ or $0.1 \mathrm{M} \mathrm{NaOH}$. The beaker was covered with aluminum foil during adsorption to prevent evaporation of the solution. After continuous stirring for $2 \mathrm{~h}$ at $23 \pm 2{ }^{\circ} \mathrm{C}$, the adsorbent was filtered out with a $0.22 \mu \mathrm{m}$ needle filter, and the remaining $\mathrm{Cu}^{2+}$ concentration in the filtrate was measured. The results were recorded as the averages of three parallel tests.

Flame atomic absorption spectrometry (900 H, Perkin Elmer Company, USA) was employed to detect the $\mathrm{Cu}^{2+}$ concentration in the solution before and after adsorption. First, the concentration of the test solution was diluted to $1.0-5.0 \mathrm{mg} / \mathrm{L}$ with $10 \% \mathrm{HCl}$. Thereafter, $3 \mathrm{~mL}$ of the diluted solution was used to measure the $\mathrm{Cu}^{2+}$ concentration before and after adsorption. Subsequently, the concentrations of the original $\mathrm{Cu}^{2+}$ solutions were calculated according to the dilution factor. Finally, the adsorbed amount $\left(\mathrm{q}_{\mathrm{e}}\right)$ was calculated using the following equation:

$\mathrm{q}_{\mathrm{e}}=\frac{\left(\mathrm{C}_{0}-\mathrm{C}_{\mathrm{e}}\right) V}{\mathrm{~m}}$

where $C_{0}(\mathrm{mg} / \mathrm{L})$ is the initial $\mathrm{Cu}^{2+}$ concentration, $C_{e}(\mathrm{mg} / \mathrm{L})$ is the equilibrium $\mathrm{Cu}^{2+}$ concentration, $V(\mathrm{~L})$ is the volume of the $\mathrm{Cu}^{2+}$ solution, and $m(\mathrm{~g})$ is the mass of the adsorbent.

\subsubsection{Reusability Experiments}

To investigate the reusability of DNC after the adsorption of $\mathrm{Cu}^{2+}$ ions, adsorption and desorption experiments were carried out at the initial $\mathrm{pH}$ of 6 , the adsorbent dose of $5 \mathrm{~g} / \mathrm{L}$, the initial $\mathrm{Cu}^{2+}$ concentration of $1014.0 \mathrm{mg} / \mathrm{L}$, and the contact time of $2 \mathrm{~h}$. After the adsorption reaction, the solution was centrifuged at $3000 \mathrm{rpm}$ for $5 \mathrm{~min}$ to obtain a blue precipitate, which is characteristic of the presence of $\mathrm{Cu}^{2+}$. Then, $50 \mathrm{~mL} \mathrm{HCl}(0.5 \mathrm{M})$ was added and placed on a magnetic stirrer for continuous stirring. Although the blue precipitate disappeared immediately after adding $\mathrm{HCl}$, the desorption reaction was carried out for $2 \mathrm{~h}$ to ensure complete desorption. After desorption was completed, the desorbed adsorbent was obtained by centrifugal separation and used again to adsorb copper ions. The adsorption and desorption experiments were repeated five times, and the adsorbed amounts were measured each time.

\subsubsection{Adsorption Kinetics}

To analyze the adsorption rates of $\mathrm{Cu}^{2+}$ onto nanocellulose, pseudo-first-order and pseudo-second-order kinetic models were tested [29]. The pseudo-first-order kinetic equation is as follows:

$\ln \left(\mathrm{q}_{\mathrm{e}}-\mathrm{q}_{\mathrm{t}}\right)=\ln \mathrm{q}_{\mathrm{e}}-\mathrm{k}_{1} \mathrm{t}$

where $q_{e}(\mathrm{mg} / \mathrm{g})$ is the adsorbed amount of $\mathrm{Cu}^{2+}$ at equilibrium, $q_{t}(\mathrm{mg} / \mathrm{g})$ is the adsorbed amount of $\mathrm{Cu}^{2+}$ at any time $\mathrm{t}, \mathrm{k}_{1}\left(\mathrm{~min}^{-1}\right)$ is the rate constant of pseudo-first-order adsorption, and $t(\mathrm{~min})$ is the contact time.

The pseudo-second-order kinetic equation is as follows:

$\frac{\mathrm{t}}{\mathrm{q}_{\mathrm{t}}}=\frac{1}{\mathrm{k}_{2} \mathrm{q}_{\mathrm{e}}^{2}}+\frac{\mathrm{t}}{\mathrm{q}_{\mathrm{e}}}$

where $q_{e}(\mathrm{mg} / \mathrm{g})$ and $q_{t}(\mathrm{mg} / \mathrm{g})$ are the adsorption capacities of copper ions $(\mathrm{mg} / \mathrm{g})$ at the time of equilibrium and time $\mathrm{t}$, respectively; $k_{2}(\mathrm{~g} / \mathrm{mg} \mathrm{min})$ is the adsorption rate constant of the pseudo-second-order adsorption; and $t(\mathrm{~min})$ is the contact time.

\subsubsection{Adsorption Isotherm Models}

Adsorption isotherms are predominantly used to study the relationship between the concentration of heavy metal ions adsorbed on the adsorbent and the equilibrium concentration of the solution and can 
help elucidate the equilibrium adsorption mechanism between solid substances and solutions. The Langmuir and Freundlich models are the most frequently used isotherm models.

The Langmuir adsorption model is assumed for monolayer adsorption, and the active adsorption sites are uniformly distributed on the surface of the adsorbent. The equation is as follows [30]:

$\mathrm{q}_{\mathrm{e}}=\frac{\mathrm{q}_{\mathrm{m}} \mathrm{K}_{\mathrm{L}} \mathrm{C}_{\mathrm{e}}}{1+\mathrm{K}_{\mathrm{L}} \mathrm{C}_{\mathrm{e}}}$

where $q_{e}(\mathrm{mg} / \mathrm{g})$ is the adsorbed amount of metal ions at equilibrium, $q_{m}(\mathrm{mg} / \mathrm{g})$ is the maximum adsorption capacity corresponding to complete monolayer coverage, $K_{L}(\mathrm{~L} / \mathrm{mg})$ is the Langmuir constant and is related to the affinity of the binding sites, and $C_{e}(\mathrm{mg} / \mathrm{L})$ is the equilibrium adsorbate concentration.

The Freundlich model assumes heterogeneous multilayer adsorption, which means that the distribution of the adsorption sites on the surface of the adsorbent is not fixed, and the equation is as follows [31]:

$\mathrm{q}_{\mathrm{e}}=\mathrm{K}_{\mathrm{F}} \mathrm{C}_{\mathrm{e}}^{\mathrm{n}}$

where $C_{e}(\mathrm{mg} / \mathrm{L})$ is the equilibrium adsorbate concentration, $q_{e}(\mathrm{mg} / \mathrm{g})$ is the amount of metal ions adsorbed at equilibrium, $K_{F}(\mathrm{~L} / \mathrm{mg})$ is the Freundlich adsorption constant, and $n$ is a parameter related to the adsorption strength.

\section{Results and Discussion}

\subsection{XRD and FTIR Spectroscopy Analysis}

XRD is used to analyze the crystal form and crystallinity of DNC. The XRD patterns of MCC and DNC are shown in Fig. 1a, the DNC have three main peaks at $15.1^{\circ}, 16.3^{\circ}$, and $22.8^{\circ} 2 \theta$ corresponding to the Miller indices of (1 10$)$, (110) and (200); the characteristic peaks of cellulose Type I are preserved, and the DNC is categorized as Type I cellulose, the crystal form has not changed after the reaction [27]. The crystallization indices of MCC and DNC were $79.1 \%$ and $76.4 \%$, respectively.
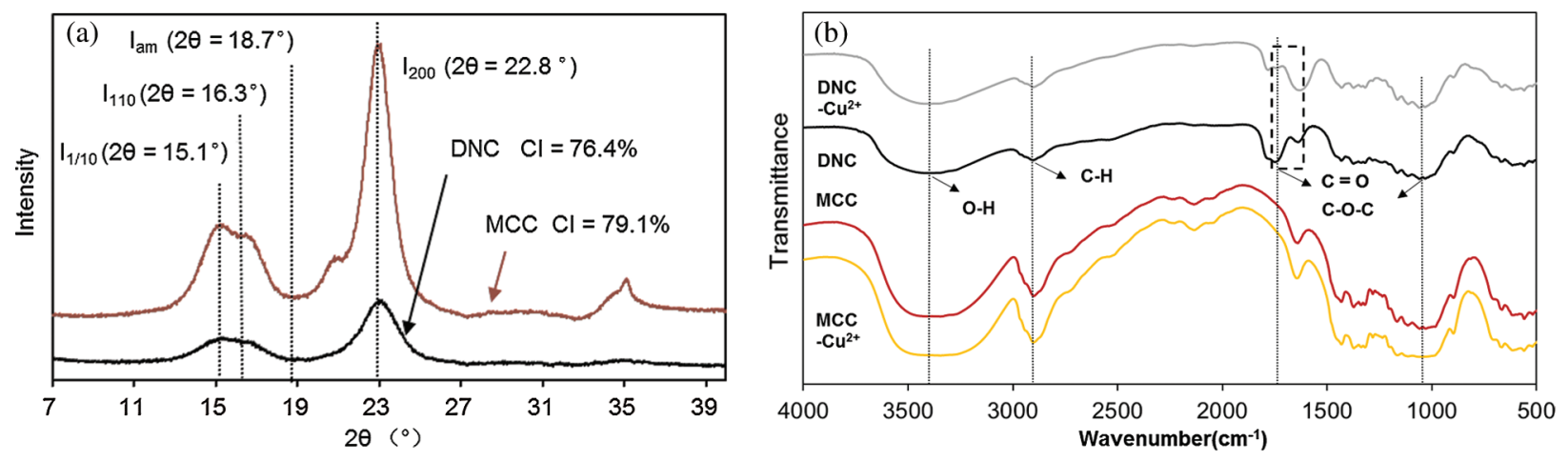

Figure 1: (a) XRD patterns of MCC and DNC, (b) FTIR spectra of MCC and DNC before and after $\mathrm{Cu}^{2+}$ adsorption

Fig. 1b shows the FTIR spectra of MCC and DNC before and after $\mathrm{Cu}^{2+}$ adsorption. The characteristic peaks of cellulose were observed, such as the hydrogen-bonded $\mathrm{O}-\mathrm{H}$ stretch at $3400 \mathrm{~cm}^{-1}$, the sp ${ }^{3}$ hybridized $\mathrm{C}-\mathrm{H}$ stretching vibration at $2900 \mathrm{~cm}^{-1}$, the $\mathrm{C}-\mathrm{O}-\mathrm{C}$ stretching vibration at $1020 \mathrm{~cm}^{-1}$, and the absorption peak of $-\mathrm{OH}$ in the dimer at $890 \mathrm{~cm}^{-1}$. Before and after $\mathrm{Cu}^{2+}$ adsorption, no significant difference was observed between MCC and $\mathrm{MCC}-\mathrm{Cu}^{2+}$, which showed that little $\mathrm{Cu}^{2+}$ was adsorbed onto MCC [12]. This is consistent with the results of Garba et al. that the adsorption capacity of unmodified MCC is low due to the lack of strong binding sites for heavy metals [32]. The FTIR spectra of DNC and 
DNC- $-\mathrm{Cu}^{2+}$ were significantly different from those of $\mathrm{MCC}$ and $\mathrm{MCC}-\mathrm{Cu}^{2+}$ from 1700 to $1800 \mathrm{~cm}^{-1}$, because the $\mathrm{C}=\mathrm{O}$ stretching vibration was observed in the $\mathrm{DNC}$ spectra. It could be explained that carboxyl groups appeared on the surface of DNC, and the hydroxyl groups in the molecular chain of cellulose were oxidized to carboxyl groups [33]. The FTIR spectra of DNC- $\mathrm{Cu}^{2+}$ were significantly different from those of DNC in the range of $1650-1750 \mathrm{~cm}^{-1}$, in which the bending and in-plane vibrations of heavy metal atoms were observed in the FTIR spectra of DNC-Cu ${ }^{2+}$ [34]. The wavenumbers from $1650-1750 \mathrm{~cm}^{-1}$ belong to the stretching vibration region of the carboxyl group, which demonstrated that the carboxyl groups were involved in the coordination of $\mathrm{Cu}^{2+}$.

\subsection{Content of Carboxyl Groups and TEM and SEM Analysis}

Steric hindrance and repulsion forces prevent hydrated metal ions from utilizing all the active sites afforded by the carboxylic groups accumulated on the surface of nanocellulose. A large amount of the appropriate functionalities should exist on the surface of the adsorbent for the adsorption of $\mathrm{Cu}^{2+}$; furthermore, a relatively high surface area is required. The content of carboxyl groups on DNC is 3.4 $\mathrm{mmol} / \mathrm{g}$, which is approximately double the carboxyl content of MNC prepared by TEMPO-mediated oxidation [35]. The TEM image of DNC is shown in Fig. 2. The morphology of DNC is short and rodshaped, with thin ends and is thick in the middle. The diameter, aspect ratio, and specific surface area (SSA) of DNC were $5.3 \pm 1.8 \mathrm{~nm}(\mathrm{n}=200), 20.6$, and $500 \mathrm{~m}^{2} / \mathrm{g}\left(\mathrm{SSA}=4 / \rho \mathrm{d}, \rho=1500 \mathrm{~kg} / \mathrm{m}^{3}, \mathrm{~d}=5.3 \mathrm{~nm}\right)$. The abundant carboxyl groups and high specific surface area can provide many reaction sites for the adsorption of copper ions. The SEM images before and after the adsorption of $\mathrm{Cu}^{2+}$ are shown in Fig. 3. Fig. 3 b shows that the square-planar $\mathrm{Cu}^{2+}$ moiety was scattered on the surface of the DNC [36,37].

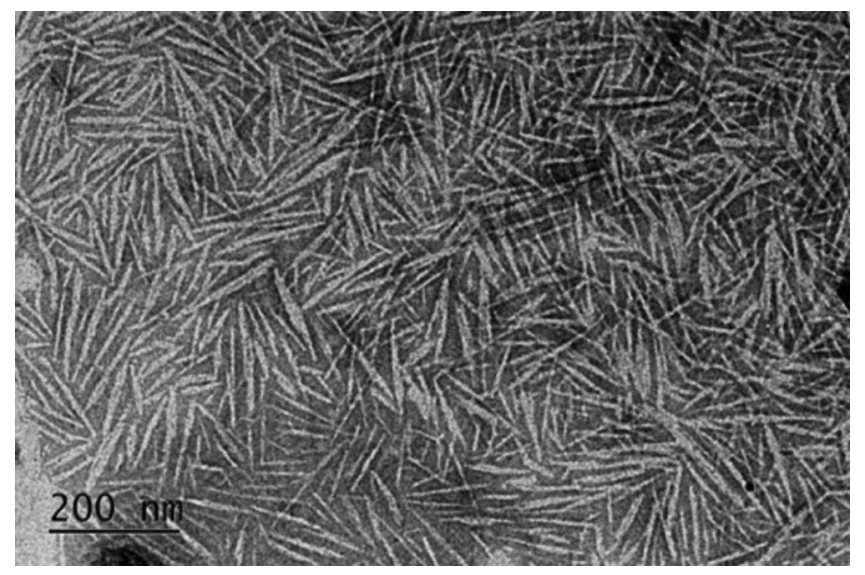

Figure 2: Transmission electron microscopy image of DNC

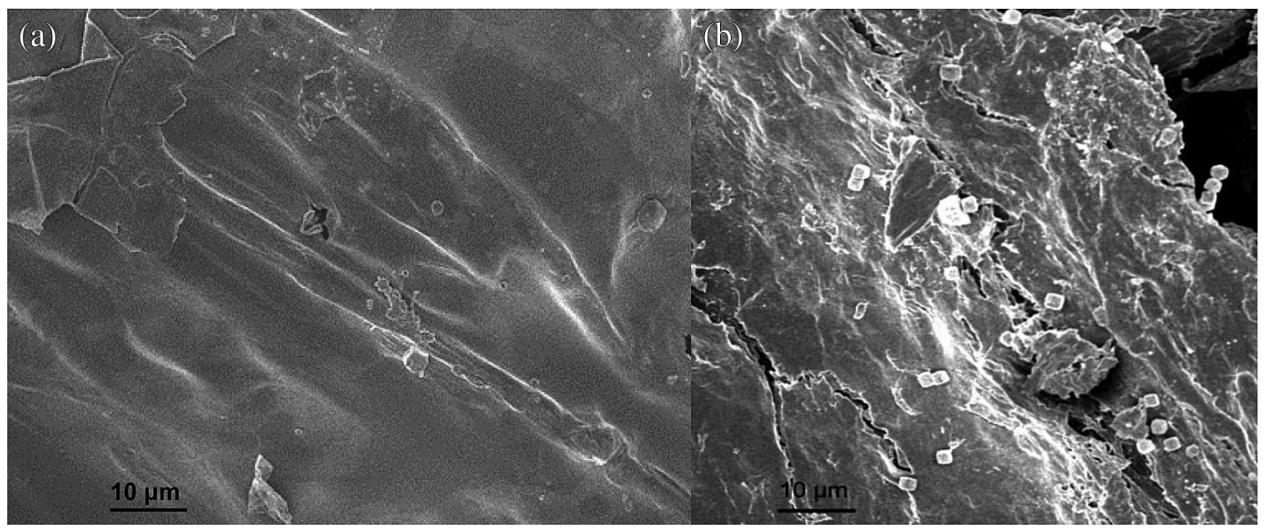

Figure 3: Scanning electron microscopy images of DNC before (a) and after (b) $\mathrm{Cu}^{2+}$ adsorption 


\subsection{Effects of Initial pH, Adsorbent Dose, Initial $\mathrm{Cu}^{2+}$ Concentration, and Contact Time on Adsorption Amount}

The effects of the initial $\mathrm{pH}$ value, adsorbent dose, initial $\mathrm{Cu}^{2+}$ concentration, and contact time on the $\mathrm{Cu}^{2+}$ adsorption capacities of DNC were studied. The experimental design and results are presented in Tab. 1 . The effect of the initial $\mathrm{pH}$ on adsorption amount is shown in Fig. 4a, the adsorbed amount of $\mathrm{Cu}^{2+}$ increased from 63.6 to $157.6 \mathrm{mg} / \mathrm{g}$ as the initial $\mathrm{pH}$ of the $\mathrm{Cu}^{2+}$ solution increased from 1 to 6 . The $\mathrm{pH}$ of the solution is an important factor affecting the $\mathrm{Cu}^{2+}$ adsorption amount [10,38]. These results can be explained by the protonation of carboxyl groups, which cannot trap $\mathrm{Cu}^{2+}$ at low $\mathrm{pH}$ values. The lower $\mathrm{pH}$ values provide a higher $\mathrm{H}^{+}$concentration, which strongly competes with $\mathrm{Cu}^{2+}$ for adsorption on the adsorption sites of the DNC, thus reducing the adsorbed amount of $\mathrm{Cu}^{2+}[14]$. With increasing $\mathrm{pH}$, the free $\mathrm{H}^{+}$in the system gradually decreases, and the negative impact of competitive adsorption on the DNC adsorption of $\mathrm{Cu}^{2+}$ ions decrease. In addition, the increase in $\mathrm{pH}$ facilitates the conversion of carboxylic groups on the surface of DNC into electronegative carboxylate ions, and the adsorbed amount of DNC increases. Because copper hydroxide precipitation occurred for $\mathrm{pH}$ values higher than 6.2 [10], the following adsorption experiments were carried out at $\mathrm{pH} 6.0$ to avoid the influence of copper hydroxide precipitation on the results of the adsorption experiment [35].

Table 1: Experimental design and results

\begin{tabular}{|c|c|c|c|c|c|}
\hline No. & Factor & $\begin{array}{l}\text { DNC dose } \\
(\mathrm{g} / \mathrm{L})\end{array}$ & $\begin{array}{l}\mathrm{Cu}^{2+} \text { concentration } \\
(\mathrm{mg} / \mathrm{L})\end{array}$ & $\begin{array}{l}\text { Initial } \\
\mathrm{pH}\end{array}$ & $\begin{array}{l}\text { Mean adsorbed amount } \pm \\
\text { S.D. }(\mathrm{mg} / \mathrm{g})\end{array}$ \\
\hline 1 & $\mathrm{pH}$ & 5.0 & 1171.20 & 1 & $63.60 \pm 10.46$ \\
\hline 2 & & 5.0 & 1171.20 & 2 & $71.84 \pm 8.13$ \\
\hline 3 & & 5.0 & 1171.20 & 3 & $95.64 \pm 9.67$ \\
\hline 4 & & 5.0 & 1171.20 & 4 & $123.24 \pm 7.35$ \\
\hline 5 & & 5.0 & 1171.20 & 5 & $143.94 \pm 8.89$ \\
\hline 6 & & 5.0 & 1171.20 & 6 & $157.56 \pm 4.83$ \\
\hline 7 & DNC dose & 2.5 & 1219.20 & 6 & $176.64 \pm 13.15$ \\
\hline 8 & & 5.0 & 1219.20 & 6 & $101.76 \pm 10.09$ \\
\hline 9 & & 10.0 & 1219.20 & 6 & $41.92 \pm 4.70$ \\
\hline 10 & & 15.0 & 1219.20 & 6 & $30.29 \pm 3.02$ \\
\hline 11 & & 20.0 & 1219.20 & 6 & $20.64 \pm 2.15$ \\
\hline 12 & & 25.0 & 1219.20 & 6 & $14.50 \pm 1.55$ \\
\hline 13 & $\mathrm{Cu}^{2+}$ & 5.0 & 51.60 & 6 & $7.42 \pm 13.15$ \\
\hline 14 & concentration & 5.0 & 127.50 & 6 & $22.36 \pm 2.11$ \\
\hline 15 & & 5.0 & 201.60 & 6 & $37.30 \pm 7.26$ \\
\hline 16 & & 5.0 & 252.10 & 6 & $47.18 \pm 6.68$ \\
\hline 17 & & 5.0 & 607.00 & 6 & $118.50 \pm 13.72$ \\
\hline 18 & & 5.0 & 1014.00 & 6 & $184.20 \pm 14.74$ \\
\hline
\end{tabular}



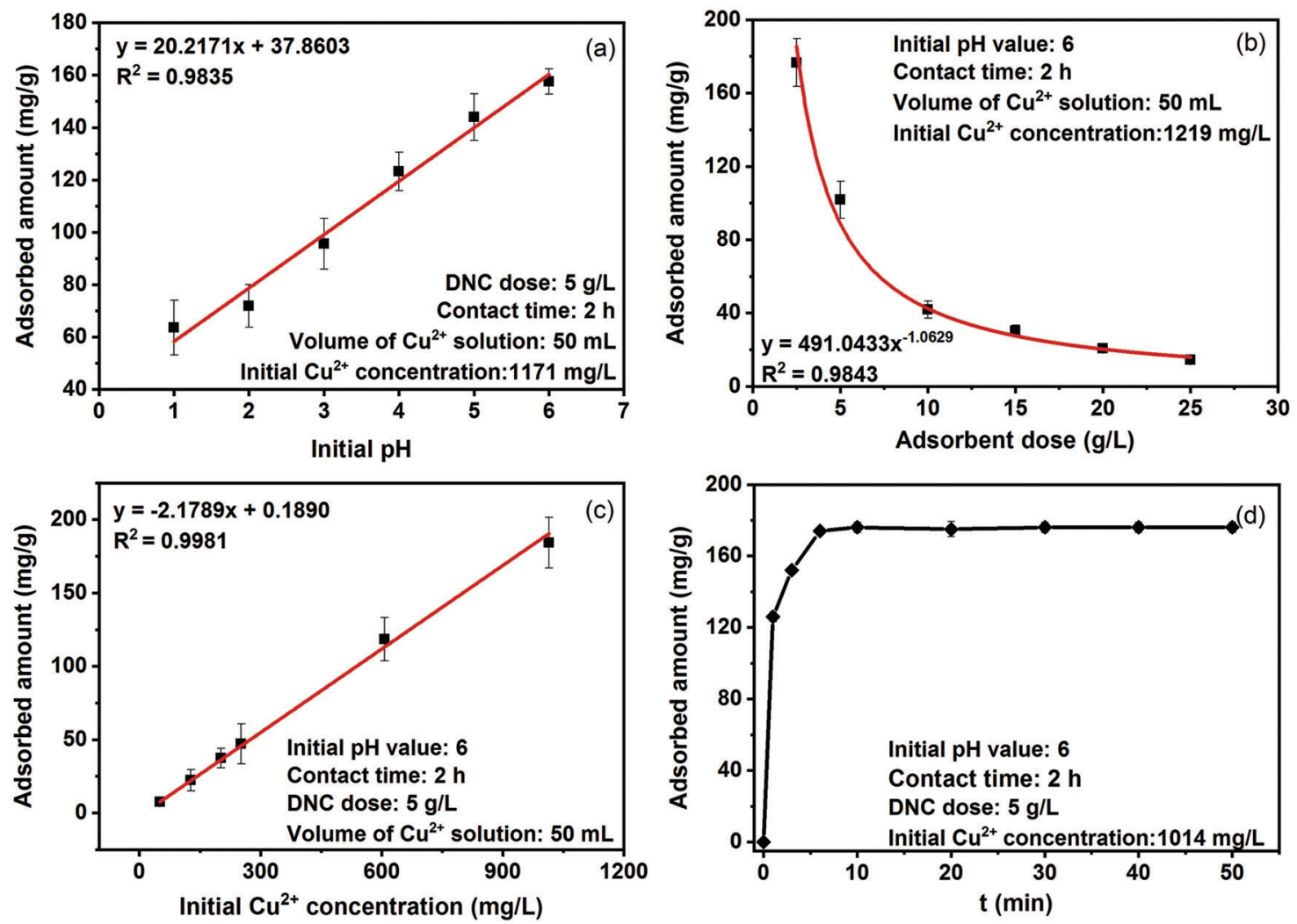

Figure 4: Effects of the initial pH. (a) DNC dose (b) initial $\mathrm{Cu}^{2+}$ concentration (c) and contact time (d) on adsorption amount

As shown in Fig. 4b, the amount of $\mathrm{Cu}^{2+}$ adsorbed onto DNC decreased with increasing adsorbent dose. The results of the present study agree with the results of Sheikhi et al. [39]. The main reason for this trend is that the concentration of remaining $\mathrm{Cu}^{2+}$ in the liquid phase is higher under low adsorbent doses and the equilibrium level of the system is higher, resulting in a high adsorption amount. The concentration of the remaining $\mathrm{Cu}^{2+}$ in the system was lower at the higher adsorbent dose, and the adsorbed amount of the system was close to saturation. However, most of the adsorption sites of DNC were still unsaturated, and the adsorbed amount of DNC was low. Therefore, it is of great significance to choose a reasonable dose of $\mathrm{DNC}$ for $\mathrm{Cu}^{2+}$-adsorption engineering.

Adsorption experiments were performed by varying the initial $\mathrm{Cu}^{2+}$ concentration from 50 to $1000 \mathrm{mg} / \mathrm{L}$ to investigate the effect of the initial $\mathrm{Cu}^{2+}$ concentration on the adsorbed amount (Fig. 4c). The adsorbed amount increased with increasing initial $\mathrm{Cu}^{2+}$ concentration, which suggested that the maximum $\mathrm{Cu}^{2+}$ adsorption capacity of DNC was not achieved under the conditions of this study. When the $\mathrm{pH}$ value was kept constant at 6 , the amount of $\mathrm{Cu}^{2+}$ adsorbed was affected by the increase in the initial copper concentration. At low $\mathrm{Cu}^{2+}$ concentrations, $\mathrm{Cu}^{2+}$ adsorption involves only higher-energy surface sites, resulting in a lower adsorption amount. At higher $\mathrm{Cu}^{2+}$ concentrations, both the higher- and lower-energy surface sites could adsorb copper ions, resulting in a higher adsorbed amount [40]. The maximum adsorption capacity reached $184.2 \mathrm{mg} / \mathrm{g}$ at $\mathrm{pH} 6$ and an adsorbent dose of $5 \mathrm{~g} / \mathrm{L}$.

As shown in Fig. 4d, the amount of $\mathrm{Cu}^{2+}$ adsorbed sharply increased to $176.0 \mathrm{mg} / \mathrm{g}$ within $10 \mathrm{~min}$, and little change was observed after $10 \mathrm{~min}$. At the initial stage of adsorption, there are considerably many electronegative carboxyl groups on the surface of DNC, and the copper ions in the solution rapidly 
complex with the carboxyl groups, occupying most of the adsorption sites. After $10 \mathrm{~min}$, few adsorption sites remained on the DNC surface, and because of the steric hindrance effect, the adsorbed amount of copper ions increased slightly when the contact time was increased. The adsorption rate of $\mathrm{Cu}^{2+}$ by DNC is fast, and the adsorption equilibrium can be reached within $10 \mathrm{~min}$.

\subsection{Adsorbent Regeneration Experiments}

The adsorption capacity of DNC was taken as $100 \%$ when it first adsorbed $\mathrm{Cu}^{2+}$, and after the first desorption and re-adsorption, the adsorbed amount decreased to $96 \%$ (Fig. 5). Thereafter, the adsorbed amount tended to stabilize with an increasing number of desorption cycles. After desorption and readsorption for five cycles, the adsorbed amount was still above $90 \%$, proving that the DNC could be recycled through desorption and regeneration in the adsorption of heavy metal ions. The adsorbed amount of DNC decreases after desorption because although hydrochloric acid desorption of $\mathrm{Cu}^{2+}$ can effectively remove $\mathrm{Cu}^{2+}$ by competitive adsorption, the process of desorption leads to protonation of carboxylic groups on the DNC surface and increases the adsorption difficulty. This causes the $\mathrm{Cu}^{2+}$ adsorbed amount to decrease, while DNC remains in the form of carboxylic acid after hydrochloric acid desorption; therefore, the continuous increase in desorption cycles has little influence on the adsorption amount.

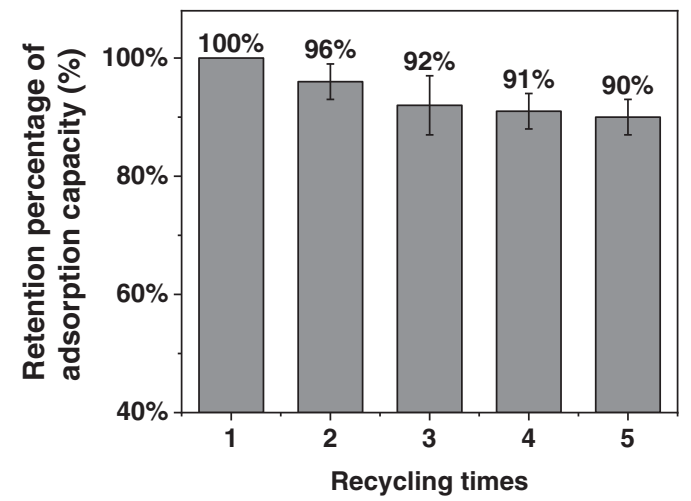

Figure 5: Relationship between recycling times and retention percentage of adsorption capacity for copper ions

\subsection{Adsorption Kinetics of Copper ion Removal by DNC}

Pseudo-first-order and pseudo-second-order kinetic models were used to investigate the kinetics of $\mathrm{Cu}^{2+}$ removal by DNC (Tab. 2). The determination coefficient $\left(\mathrm{R}^{2}\right)$ values were 0.6187 and 0.9998 for the pseudofirst-order and pseudo-second-order kinetic models, respectively. Therefore, the adsorption kinetics of $\mathrm{Cu}^{2+}$ by $\mathrm{DNC}$ can be explained by the pseudo-second-order kinetic model, indicating that $\mathrm{Cu}^{2+}$ adsorption onto $\mathrm{DNC}$ is a chemisorption process.

Table 2: Kinetic parameters for copper adsorption onto DNC

\begin{tabular}{llllll}
\hline \multicolumn{2}{l}{ Pseudo-first-order model } & \multicolumn{5}{c}{ Pseudo-second-order model } \\
\hline $\mathrm{k}_{1}\left(\mathrm{~min}^{-1}\right)$ & $\mathrm{q}_{\mathrm{e}}(\mathrm{mg} / \mathrm{g})$ & $\mathrm{R}^{2}$ & $\mathrm{k}_{2}(\mathrm{~g} /(\mathrm{mg} \min ))$ & $\mathrm{q}_{\mathrm{e}}(\mathrm{mg} / \mathrm{g})$ & $\mathrm{R}^{2}$ \\
0.0356 & 1.56 & 0.6187 & 0.297 & 183.48 & 0.9998 \\
\hline
\end{tabular}




\subsection{Adsorption Isotherms}

Langmuir and Freundlich isotherm models were used to obtain the isotherm parameters for the adsorption of $\mathrm{Cu}^{2+}$ ions onto DNC (Tab. 3). The determination coefficients $\left(\mathrm{R}^{2}\right)$ values were 0.9991 and 0.6187 for Langmuir and Freundlich models, respectively. The adsorption data of $\mathrm{Cu}^{2+}$ onto DNC fit well with the Langmuir model; therefore, the distribution of adsorption sites on the DNC surface is uniform, and the adsorption of $\mathrm{Cu}^{2+}$ onto DNC has the characteristics of monolayer adsorption. The results were consistent with those described in Section 3.2. The maximum adsorption capacity of $\mathrm{Cu}^{2+}$ onto DNC was $217.4 \mathrm{mg} / \mathrm{g}$, as calculated by the Langmuir model.

Table 3: Langmuir and freundlich parameters for copper ion adsorption onto the DNC

\begin{tabular}{llllll}
\hline \multicolumn{2}{l}{ Langmuir model } & \multicolumn{5}{l}{ Freundlich model } \\
\hline $\mathrm{q}_{\mathrm{m}}(\mathrm{mg} / \mathrm{g})$ & $\mathrm{K}_{\mathrm{L}}(\mathrm{L} / \mathrm{mg})$ & $\mathrm{R}^{2}$ & $\mathrm{~K}_{\mathrm{F}}(\mathrm{L} / \mathrm{mg})$ & $\mathrm{n}$ & $\mathrm{R}^{2}$ \\
217.4 & 0.2541 & 0.9991 & 1.318 & 1.9627 & 0.6187 \\
\hline
\end{tabular}

\subsection{Study on the Maximum Adsorption Capacity of Carboxylic Nanocellulose}

The adsorption of $\mathrm{Cu}^{2+}$ by carboxylic nanocellulose was mainly achieved through the adsorption of $\mathrm{Cu}^{2+}$ by carboxyl and hydroxyl sites, and carboxyl groups were found to be more effective in adsorbing $\mathrm{Cu}^{2+}$ than hydroxyl groups [22,41]. The possible complexations of $\mathrm{Cu}^{2+}$ with carboxyl groups on the surface of carboxylic nanocellulose can be summarized in the following reactions [37,39]. First, the $\mathrm{Cu}$ $(\mathrm{OH})^{+}$and $\mathrm{Cu}(\mathrm{COO})^{+}$are generated by the $\mathrm{Cu}^{2+}$ combining with $\mathrm{OH}^{-}$and $\mathrm{COO}^{-}$in the solution. Then, two different forms of complexes $\left(\mathrm{Cu}(\mathrm{COO})_{2}\right.$ and $\left.\mathrm{Cu}(\mathrm{COO})(\mathrm{OH})\right)$ are generated by the complexation of the $\mathrm{Cu}(\mathrm{OH})^{+}$and $\mathrm{Cu}(\mathrm{COO})^{+}$with a large number of $\mathrm{COO}^{-}$on the surface of DNC.

$\mathrm{COOH} \rightleftharpoons \mathrm{COO}^{-}+\mathrm{H}^{+}$

$\mathrm{Cu}^{2+}+\mathrm{OH}^{-} \rightleftharpoons \mathrm{Cu}(\mathrm{OH})^{+}$

$\mathrm{Cu}^{2+}+\mathrm{COO}^{-} \rightleftharpoons \mathrm{Cu}(\mathrm{COO})^{+}$

$\mathrm{COO}^{-}+\mathrm{Cu}(\mathrm{COO})^{+} \rightleftharpoons \mathrm{Cu}(\mathrm{COO})_{2}$

$\mathrm{COO}^{-}+\mathrm{Cu}(\mathrm{OH})^{+} \rightleftharpoons \mathrm{Cu}(\mathrm{COO})(\mathrm{OH})$

According to Eqs. (8)-(12), the theoretical maximum adsorption capacity of carboxyl groups can be calculated as follows:

$\mathrm{q}\left(\mathrm{COO}^{-}\right)=\frac{2 \times \mathrm{c}\left(\mathrm{COO}^{-}\right)}{3} \times \mathrm{M}$

where $q\left(\mathrm{COO}^{-}\right)$is the theoretical maximum adsorption capacity of carboxyl groups, $c\left(\mathrm{COO}^{-}\right)$is the molarity of the carboxyl groups, and $M$ is the relative atomic mass of $\mathrm{Cu}^{2+}$.

Because one five-membered stable chelate is formed by every four hydroxyl groups and one $\mathrm{Cu}^{2+}$ ion, the theoretical maximum adsorption amount of hydroxyl groups can be calculated as follows [36]:

$\mathrm{q}(-\mathrm{OH})=\frac{\mathrm{c}(\mathrm{OH})}{4} \times \mathrm{M}$

where $q(-\mathrm{OH})$ is the theoretical maximum adsorption capacity of hydroxyl groups, $c(-\mathrm{OH})$ is the molarity of hydroxyl groups, and $M$ is the relative atomic mass of $\mathrm{Cu}^{2+}$. 
The theoretical maximum adsorption capacity of carboxylic nanocellulose $\left(q_{\max }\right)$ with carboxyl and hydroxyl groups on copper ions is as follows:

$\mathrm{q}_{\max }=\mathrm{q}\left(\mathrm{COO}^{-}\right)+\mathrm{q}(-\mathrm{OH})=\frac{2 \times \mathrm{c}\left(\mathrm{COO}^{-}\right) \times \mathrm{M}}{3}+\frac{\mathrm{c}(-\mathrm{OH}) \times \mathrm{M}}{4}$

The glucose rings in the molecular chain structure of cellulose are alternately distributed, i.e., the functional groups at C2, C3, and C6 are alternately distributed [42]. Therefore, the mole number of the exposed hydroxyl groups is twice that of the carboxyl groups along the cellulose molecular chain in MNC, while the mole number of hydroxyl groups is half that of carboxyl groups in DNC. Although the theoretical maximum adsorption capacity in Eq. (14) is calculated from the carboxyl and hydroxyl content, the carboxyl content can be calculated from the hydroxyl content, so the theoretical maximum adsorption capacity of carboxylic nanocellulose can be calculated using only the carboxyl content.

According to our previous study [19], the maximum carboxyl contents of MNC, DNC, and TNC were $3.0865,6.1727$, and $9.2592 \mathrm{mmol} / \mathrm{g}$, respectively.

For $\mathrm{MNC}$, only the hydroxyl groups at the $\mathrm{C} 6$ site are oxidized to carboxyl groups, and the four hydroxyl groups at the $\mathrm{C} 2$ and $\mathrm{C} 3$ sites can capture one $\mathrm{Cu}^{2+}$ ion [36]. Therefore, the theoretical maximum adsorption capacity of the MNC is calculated as follows:

$\mathrm{q}(\mathrm{C} 6)=\mathrm{q}\left(\mathrm{COO}^{-}\right)+\mathrm{q}(-\mathrm{OH})=\frac{2 \times \mathrm{c}\left(\mathrm{COO}^{-}\right) \times \mathrm{M}}{3}+\frac{2 \times \mathrm{c}\left(\mathrm{COO}^{-}\right) \times \mathrm{M}}{4}=228.7 \mathrm{mg} / \mathrm{g}$

For DNC, the hydroxyl groups at the $\mathrm{C} 2$ and $\mathrm{C} 3$ sites are oxidized to carboxyl groups, and it is difficult for the one hydroxyl group remaining at the C6 site to capture copper ions alone [36,41]. Therefore, the theoretical maximum adsorption capacity of DNC was calculated as follows:

$\mathrm{q}(\mathrm{C} 2, \mathrm{C} 3)=\mathrm{q}\left(\mathrm{COO}^{-}\right)=\frac{2 \times \mathrm{c}\left(\mathrm{COO}^{-}\right) \times \mathrm{M}}{3}=261.3 \mathrm{mg} / \mathrm{g}$

For TNC, the hydroxyl groups at the $\mathrm{C} 6, \mathrm{C} 2$, and $\mathrm{C} 3$ sites are oxidized to carboxyl groups. The length of cellobiose, the basic unit of cellulose, is $1.03 \mathrm{~nm}$ [42], while the ionic diameter of $\mathrm{Cu}^{2+}$ ions in water is $1.2 \mathrm{~nm}$ [43]. For TNC, three anhydroglucose units are required to capture one $\mathrm{Cu}^{2+}$ ion because of steric hindrance, that is, 4 moles of carboxylate ions capture $1 \mathrm{~mol}$ of copper ions. Therefore, the theoretical maximum adsorption capacity of TNC was calculated as follows:

$\mathrm{q}(\mathrm{C} 2, \mathrm{C} 3, \mathrm{C} 6)=\mathrm{q}\left(\mathrm{COO}^{-}\right)=\frac{\mathrm{c}\left(\mathrm{COO}^{-}\right) \times \mathrm{M}}{4}=148.1 \mathrm{mg} / \mathrm{g}$

The theoretical maximum adsorption capacities of $\mathrm{Cu}^{2+}$ for MNC, DNC, and TNC were 228.7, 261.3, and $148.1 \mathrm{mg} / \mathrm{g}$, respectively. Tab. 4 compares the results of our theoretical calculations with those of the other methods. The results of this study were closer to the experimental results from other studies. Therefore, the current results were used to investigate the adsorption cost of carboxylic nanocellulose for copper ions. 
Table 4: Comparison of results from different calculation methods

\begin{tabular}{|c|c|c|c|c|c|}
\hline & \multicolumn{3}{|c|}{$\begin{array}{l}\text { Maximum adsorption capacity of } \\
\text { calculated theoretically }(\mathrm{mg} / \mathrm{g})^{\mathrm{a}}\end{array}$} & \multirow[t]{2}{*}{$\begin{array}{l}\text { Experimental results } \\
\text { from references }(\mathrm{mg} / \mathrm{g})\end{array}$} & \multirow[t]{2}{*}{ Reference } \\
\hline & I & II & III & & \\
\hline $\mathrm{MNC}$ & 182.8 & 243.8 & 228.7 & $\begin{array}{l}145.0 \\
75.0 \\
135.0 \\
268.0\end{array}$ & $\begin{array}{l}{[44]} \\
{[20]} \\
{[14]} \\
{[45]}\end{array}$ \\
\hline DNC & 334.2 & 449.1 & 261.3 & $\begin{array}{l}185.0 \\
246.0 \\
184.2\end{array}$ & $\begin{array}{l}{[39]} \\
{[21]} \\
\text { This study }\end{array}$ \\
\hline TNC & 472.9 & 630.5 & 148.1 & $\begin{array}{l}97.3 \\
115.3\end{array}$ & $\begin{array}{l}{[13]} \\
{[22]}\end{array}$ \\
\hline PAC & - & - & - & $\begin{array}{l}95.0 \\
5.7 \\
20.8 \\
4.4 \\
31.8 \\
127.0\end{array}$ & $\begin{array}{l}{[46]} \\
{[47]} \\
{[48]} \\
{[49]} \\
{[50]} \\
{[50]}\end{array}$ \\
\hline
\end{tabular}

Note: ${ }^{a}$ Calculated method for theoretical maximum adsorption capacity: (I) determined by Maekawa's method [21,43], where two carboxyl groups are required to capture one copper ion; (II) determined by Maekawa's method [21,43], where three carboxyl groups are required to capture two copper ions; and (III) determined by the method described in this study. $\mathrm{MNC}=$ monocarboxylic nanocellulose; $\mathrm{DNC}=$ dicarboxylic nanocellulose; $\mathrm{TNC}=$ tricarboxylic nanocellulose; PAC = powdered activated carbon.

\subsection{Adsorption Cost of $\mathrm{Cu}^{2+}$ onto Carboxylic Nanocellulose}

The PAC price of \$0.8-2.0 per kg collected from Chinese manufacturers in 2020 was used to analyze the adsorption cost of PAC (Tab. 5). The price data for carboxylic nanocellulose were collected from Chinese manufacturers or suppliers. The price of carboxylic nanocellulose is highly volatile and may range from \$77.2-231.7 per kg (dry weight). According to the results of previous research, carboxylic nanocellulose can be recycled at least five times through desorption and regeneration.

Table 5: Price range, theoretical maximum adsorption capacity, and number of recycles of powdered activated carbon and carboxylic nanocellulose

\begin{tabular}{llll}
\hline Adsorbent & Price range $(\$ / \mathrm{kg})$ & $\begin{array}{l}\text { Theoretical maximum } \\
\text { adsorption capacity }(\mathrm{mg} / \mathrm{g})\end{array}$ & Cycles \\
\hline PAC & $\$ 0.8-2.0$ & $127.0[50]$ & 1 \\
MNC & $\$ 77.2-231.7$ & 228.7 (this study) & 5 \\
DNC & $\$ 77.2-231.7$ & 261.3 (this study) & 5 \\
TNC & $\$ 77.2-231.7$ & 148.1 (this study) & 5 \\
\hline
\end{tabular}

Note: $\mathrm{PAC}=$ powdered activated carbon; $\mathrm{MNC}=$ monocarboxylic nanocellulose; $\mathrm{DNC}=$ dicarboxylic nanocellulose; TNC $=$ tricarboxylic nanocellulose. 
The adsorption costs of $\mathrm{Cu}^{2+}$ ions for MNC, DNC, TNC, and PAC are shown in Fig. 6. As shown in Fig. 6a, the $\mathrm{Cu}^{2+}$ adsorption costs of carboxylic nanocelluloses were higher than those of PAC, and the maximum multiple could even reach 500 times when no regeneration was conducted. The fluctuation ranges of the adsorption cost were \$288.2-3089.8, and \$6.08-456.4 per kg of carboxylic nanocelluloses and PAC, respectively. When five regeneration cycles were performed for carboxylic nanocelluloses, there was an overlapping area of adsorption cost between carboxylic nanocelluloses and PAC (Fig. 6b). The $\mathrm{Cu}^{2+}$ adsorption cost of DNC $\left(\$ 59.1-286.09\right.$ per $\left.\mathrm{kg} \mathrm{Cu}^{2+}\right)$ is especially likely to be lower than those of PAC $\left(\$ 6.08-456.4\right.$ per $\left.\mathrm{kg} \mathrm{Cu}{ }^{2+}\right)$. These results indicate that the carboxylic nanocellulose must be recycled to compete with PAC in terms of adsorption cost. In addition, the price of PAC was the price of industrial-scale production, while the price of DNC was the price of small-scale production. With the expansion of DNC production scale, the price of DNC is expected to drop sharply. Therefore, considering the adsorption capacity, reusability and adsorption cost, the DNC prepared by sequential oxidation of $\mathrm{NaIO}_{4}-\mathrm{NaClO}_{2}$ has the potential to compete with PAC in the treatment of wastewater containing $\mathrm{Cu}^{2+}$.
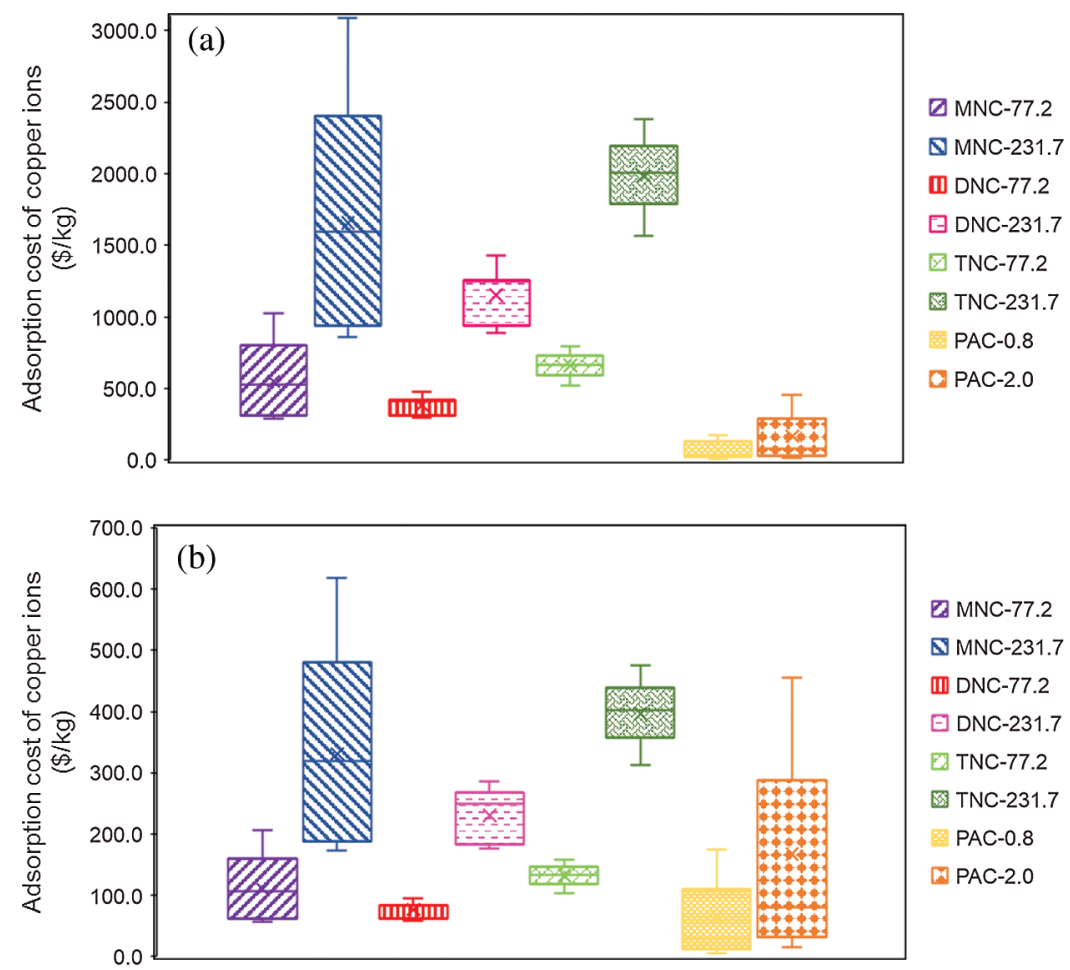

Figure 6: Fluctuation range of the adsorption cost of different adsorbents for copper ions. (a) No regeneration, (b) Five regeneration cycles for $\mathrm{MNC}, \mathrm{DNC}$, and $\mathrm{TNC}$

\section{Conclusions}

DNC was prepared from $\mathrm{MCC}$ using the $\mathrm{NaIO}_{4}-\mathrm{NaClO}_{2}$ sequential oxidation method. The higher carboxyl content of $3.4 \mathrm{mmol} / \mathrm{g}$ and high specific surface area of $500 \mathrm{~m}^{2} / \mathrm{g}$ endow DNC with a strong adsorption capacity of $184.2 \mathrm{mg} / \mathrm{g}$ for $\mathrm{Cu}^{2+}$ ions. The theoretical maximum adsorption capacities of $\mathrm{Cu}^{2+}$ for MNC, DNC, and TNC were calculated to be $228.7,261.3$, and $148.1 \mathrm{mg} / \mathrm{g}$, respectively. The $\mathrm{Cu}^{2+}$ adsorption cost of DNC is close to or lower than that of PAC, demonstrating that DNC prepared by 
$\mathrm{NaIO}_{4}-\mathrm{NaClO}_{2}$ sequential oxidation has competitive adsorption capacity and cost for the treatment of wastewater containing $\mathrm{Cu}^{2+}$.

Funding Statement: The authors received no specific funding for this study.

Conflicts of Interest: The authors declare that they have no conflicts of interest to report regarding the present study.

\section{References}

1. Blais, J. F., Djedidi, Z., Cheikh, R., Tyagi, R., Mercier, G. (2008). Metals precipitation from effluents: Review. Practice Periodical of Hazardous, Toxic, and Radioactive Waste Management, 12, 135-149. DOI 10.1061/ (ASCE)1090-025X(2008)12:3(135).

2. Liu, Y., Wu, Y., Guo, X., Wen, Y., Yang, H. (2019). Rapid and selective detection of trace $\mathrm{Cu}^{2+}$ by accumulationreaction-based Raman spectroscopy. Sensors \& Actuators B: Chemical, 283, 278-283. DOI 10.1016/j. snb.2018.12.043.

3. Demirbaş, A. (2008). Heavy metal adsorption onto agro-based waste materials: A review. Journal of Hazardous Materials, 157, 220-229. DOI 10.1016/j.jhazmat.2008.01.024.

4. Fu, F., Wang, Q. (2011). Removal of heavy metal ions from wastewaters: A review science direct. Journal of Environmental Management, 92, 407-418. DOI 10.1016/j.jenvman.2010.11.011.

5. Sxa, B., Jc, C., Hp, A., Sl, C., Hui, L. D. et al. (2021). Effect of biomass type and pyrolysis temperature on nitrogen in biochar, and the comparison with hydrochar. Fuel, 291, 120128. DOI 10.1016/j.fuel.2021.120128.

6. Leng, L., Xiong, Q., Yang, L., Li, H., Huang, H. (2021). An overview on engineering the surface area and porosity of biochar. Science of the Total Environment, 763, 144204. DOI 10.1016/j.scitotenv.2020.144204.

7. Sun, X. Z., Moon, D., Yagishita, T., Minowa, T. (2013). Evaluation of energy consumption and greenhouse gas emissions in preparation of cellulose nanofibers from woody biomass. Transactions of the ASABE, 56, 10611067. DOI 10.13031/trans.56.10040.

8. Song, L. Y., Wu, Y. Z., Pei, X. X., Li, R., Chen, H. T. et al. (2020). Pulmonary toxicity and RNA sequencing analyses of mouse in response to exposure to cellulose nanofibrils. Inhalation Toxicology, 32, 388-401. DOI $10.1080 / 08958378.2020 .1831112$.

9. van de Ven, T. G. M., Sheikhi, A. (2016). Hairy cellulose nanocrystalloids: A novel class of nanocellulose. Nanoscale, 8, 15101-15114. DOI 10.1039/c6nr01570k.

10. Abouzeid, R. E., Khiari, R., El-Wakil, N., Dufresne, A. (2019). Current state and New trends in the Use of cellulose nanomaterials for wastewater treatment. Biomacromolecules, 20, 573-597. DOI 10.1021/acs.biomac.8b00839.

11. Hokkanen, S., Bhatnagar, A., Sillanpaa, M. (2016). A review on modification methods to cellulose-based adsorbents to improve adsorption capacity. Water Research, 91, 156-173. DOI 10.1016/j.watres.2016.01.008.

12. Voisin, H., Bergstrom, L., Liu, P., Mathew, A. P. (2017). Nanocellulose-based materials for water purification. Nanomaterials, 7, 57-75. DOI 10.3390/nano7030057.

13. Abouzeid, R., Dacrory, S., Ali, K., Kamel, S. (2018). Novel method of preparation of tricarboxylic cellulose nanofiber for efficient removal of heavy metal ions from aqueous solution. Journal of Chromatography BAnalytical Technologies in the Biomedical and Life Sciences, 119, 207-214. DOI 10.1016/j.ijbiomac.2018.07.127.

14. Sehaqui, H., de Larraya, U. P., Liu, P., Pfenninger, N., Mathew, A. P. et al. (2014). Enhancing adsorption of heavy metal ions onto biobased nanofibers from waste pulp residues for application in wastewater treatment. Cellulose, 21, 2831-2844. DOI 10.1007/s10570-014-0310-7.

15. Zhang, N., Zang, G. L., Shi, C., Yu, H. Q., Sheng, G. P. (2016). A novel adsorbent TEMPO-mediated oxidized cellulose nanofibrils modified with PEI: Preparation, characterization, and application for $\mathrm{Cu}(\mathrm{II})$ removal. Journal of Hazard Materiels, 316, 11-18. DOI 10.1016/j.jhazmat.2016.05.018.

16. Çavuş, S., Gürdăg, G., Yasar, M., Güçlü, K., Gürkaynak, M. (2006). The competitive heavy metal removal by hydroxyethyl cellulose-g-poly(acrylic acid) copolymer and its sodium salt: The effect of copper content on the adsorption capacity. Polymer Bulletin, 57, 445-456. DOI 10.1007/s00289-006-0583-6. 
17. Du, Z., Zheng, T., Wang, P. (2018). Experimental and modelling studies on fixed bed adsorption for $\mathrm{Cu}(\mathrm{II})$ removal from aqueous solution by carboxyl modified jute fiber. Powder Technology, 338, 952-959. DOI 10.1016/j. powtec.2018.06.015.

18. Lu, J., Jin, R. N., Liu, C., Wang, Y. F., Ouyang, X. K. (2016). Magnetic carboxylated cellulose nanocrystals as adsorbent for the removal of $\mathrm{Pb}$ (II) from aqueous solution. International Journal of Biological Macromolecules, 93, 547-556. DOI 10.1016/j.ijbiomac.2016.09.004.

19. Song, L. Y., Pei, X., Li, R., Chen, H. T., Sun, X. Z. (2020). Preparation of cellulose nanofibrils by multi-site regioselective oxidation. Journal of Renewable Materials, 8, 1269-1273. DOI 10.32604/jrm.2020.010923.

20. Liu, P., Garrido, B., Oksman, K., Mathew, A. P. (2016). Adsorption isotherms and mechanisms of Cu(ii) sorption onto TEMPO-mediated oxidized cellulose nanofibers. RSC Advances, 6, 107759-107767. DOI 10.1039/ C6RA22397D.

21. Maekawa, E., Koshijima, T. (1984). Properties of 2,3-dicarboxy cellulose combined with various metallic ions. Journal of Applied Polymer Science, 29, 2289-2297. DOI 10.1002/app.1984.070290705.

22. Qin, F., Fang, Z., Zhou, J., Sun, C., Chen, K. et al. (2019). Efficient removal of $\mathrm{Cu}^{2+}$ in water by carboxymethylated cellulose nanofibrils: Performance and mechanism. Biomacromolecules, 20, 4466-4475. DOI 10.1021/acs.biomac.9b01198.

23. Marsh, H., Rodriguez-Reinoso, F. (2006). Activated carbon. Elsevier Science, Ltd., Oxford, UK.

24. Bulota, M., Maasdam, B., Tiekstra, S. (2013). Breakthrough technologies, more with less kenniscentrum papier en karton, pp. 1-17. https://www.docin.com/p-1810342499.html.

25. French, A. D. (2020). Increment in evolution of cellulose crystallinity analysis. Cellulose, 27, 5445-5448. DOI 10.1007/s10570-020-03172-z.

26. Segal, L., Creely, J., Martin, A. E. J., Conrad, C. (1959). An empirical method for estimating the degree of crystallinity of native cellulose using the X-ray diffractometer. Textile Research Journal, 29, 786-794. DOI $10.1177 / 004051755902901003$.

27. French, A. D. (2014). Idealized powder diffraction patterns for cellulose polymorphs. Cellulose, 21, 885-896. DOI 10.1007/s10570-013-0030-4.

28. French, A. D., Santiago Cintrón, M. (2013). Cellulose polymorphy, crystallite size, and the segal crystallinity index. Cellulose, 20, 583-588. DOI 10.1007/s10570-012-9833-y.

29. Ho, Y. S., Ng, J., McKay, G. (2000). Kinetics of pollutant sorption by biosorbents: Review. Separation and Purification Reviews, 29, 189-232. DOI 10.1081/SPM-100100009.

30. Langmuir, I. (1917). The constitution and fundamental properties of solids and liquids. Part II. Liquids. Journal of the American Chemical Society, 184, 721. DOI 10.1016/S0016-0032(17)90938-X.

31. Herbert, F. (1907). Über die adsorption in lösungen. Zeitschrift für Physikalische Chemie, 57, 385-470. DOI 10.1515/zpch-1907-5723.

32. Barczynski, P., Komasa, A., Ratajczak, M. (2011). Structure of 3,4-dicarboxy-1-methylpyridinium inner salt studied by X-ray diffraction, DFT calculations, FTIR, Raman and NMR spectra. Journal of Molecular Structure, 994, 216-222. DOI 10.1016/j.molstruc.2011.03.021.

33. Garba, Z. N., Lawan, I., Zhou, W., Zhang, M., Wang, L. et al. (2020). Microcrystalline cellulose (mcc) based materials as emerging adsorbents for the removal of dyes and heavy metals-A review. The Science of the Total Environment, 717, 135070.1-135070.21. DOI 10.1016/j.scitotenv.2019.135070.

34. Conley, K., Whitehead, M. A., van de Ven, T. G. M. (2016). Chemically peeling layers of cellulose nanocrystals by periodate and chlorite oxidation. Cellulose, 23, 1553-1563. DOI 10.1007/s10570-016-0922-1.

35. Liu, P., Oksman, K., Mathew, A. P. (2016b). Surface adsorption and self-assembly of Cu(II) ions on TEMPOoxidized cellulose nanofibers in aqueous media. Journal of Colloid \& Interface Science, 464, 175-182. DOI 10.1016/j.jcis.2015.11.033.

36. Ajiboye, S. I., Brown, D. R. (1990). Electron spin resonance study of soluble copper(II)-cellulose complexes. Journal of the Chemical Society, Faraday Transactions, 86, 65-68. DOI 10.1039/FT9908600065. 
37. Borges, F., Guimaraes, C., Lima, J. L., Pinto, I., Reis, S. (2005). Potentiometric studies on the complexation of copper(II) by phenolic acids as discrete ligand models of humic substances. Talanta, 66, 670-673. DOI 10.1016/j.talanta.2004.12.012.

38. Abouzeid, R., Salama, A., Alahmed, Z., Awwad, N., Youssef, M. (2020). Carboxylated cellulose nanofibers as a novel efficient adsorbent for water purification. Cellulose Chemical and Technology, 54, 237-245. DOI 10.35812/ CelluloseChemTechnol.

39. Sheikhi, A., Safari, S., Yang, H., van de Ven, T. G. M. (2015). Copper removal using electrosterically stabilized nanocrystalline cellulose. ACS Applied Materials \& Interfaces, 7, 11301-11308. DOI 10.1021/acsami.5b01619.

40. Kadirvelu, K., Faur-Brasquet, C., Le Cloirec, P. (2000). Removal of $\mathrm{Cu}(\mathrm{II}), \mathrm{Pb}(\mathrm{II})$, and $\mathrm{Ni}(\mathrm{II})$ by adsorption onto activated carbon cloths. Langmuir, 16, 8404-8409. DOI 10.1021/la0004810.

41. Poorsargol, M., Razmara, Z., Amiri, M. M. (2020). The role of hydroxyl and carboxyl functional groups in adsorption of copper by carbon nanotube and hybrid graphene-carbon nanotube: Insights from molecular dynamic simulation. Adsorption, 26, 397-405. DOI 10.1007/s10450-020-00214-7.

42. Bruce, S. (2005). Cellulose: Structure and distribution. Encyclopedia of life sciences, New York, John Wiley \& Sons.

43. Maekawa, E., Ueno, I., Koshijima, T. (1981). Properties and thermal behaviors of 2,3-dicarboxy cellulose metallic salts. Seni Gakkaishi, 37, 57-63 (in Japanese). DOI 10.2115/fiber.37.12_T509.

44. Zhang, L., Lu, H., Yu, J., Fan, Y., Yang, Y. et al. (2018). Synthesis of lignocellulose-based composite hydrogel as a novel biosorbent for $\mathrm{Cu}^{2+}$ removal. Cellulose, 25, 7315-7328. DOI 10.1007/s10570-018-2077-8.

45. Isobe, N., Chen, X., Kim, U. J., Kimura, S., Wada, M. et al. (2013). TEMPO-Oxidized cellulose hydrogel as a high-capacity and reusable heavy metal ion adsorbent. Journal of Hazardous Materials, 260, 195-201. DOI 10.1016/j.jhazmat.2013.05.024.

46. Reyad, A., Shawabkeha, D. A. R., Bhadab, R. K. (2002). Copper and strontium adsorption by a novel carbon material manufactured from pecan shells. Carbon, 40, 781-786. DOI 10.1016/S0008-6223(01)00198-1.

47. Kalavathy, M. H., Karthikeyan, T., Rajgopal, S., Miranda, L. R. (2005). Kinetic and isotherm studies of Cu(II) adsorption onto $\mathrm{H}_{3} \mathrm{PO}_{4}$-activated rubber wood sawdust. Journal of Colloid and Interface Science, 292, 354362. DOI 10.1016/j.jcis.2005.05.087.

48. Rao, M. M., Ramesh, A., Rao, G. P., Seshaiah, K. (2006). Removal of copper and cadmium from the aqueous solutions by activated carbon derived from ceiba pentandra hulls. Journal of Hazardous Materials, 129, $123-$ 129. DOI 10.1016/j.jhazmat.2005.08.018.

49. An, H. K., Park, B. Y., Kim, D. S. (2001). Crab shell for the removal of heavy metals from aqueous solution. Water Research, 35, 3551-3556. DOI 10.1016/S0043-1354(01)00099-9.

50. Dastgheib, S. A., Rockstraw, D. A. (2001). Pecan shell activated carbon: Synthesis, characterization, and application for the removal of copper from aqueous solution. Carbon, 39, 1849-1855. DOI 10.1016/S00086223(00)00315-8. 